Mikhail S. Ermolin* and Petr S. Fedotov

\title{
Separation and characterization of environmental nano- and submicron particles
}

DOI 10.1515/revac-2016-0006

Received February 9, 2016; accepted August 13, 2016; previously published online September 17, 2016

\begin{abstract}
The investigation of environmental nano- and submicron particles is needed for the assessment of their impact on the environment and human health as well as for understanding various natural and anthropogenic processes. Nano- and submicron particles have an increased mobility, may serve as a "carrier" for toxic and nutrient substances, and hence are of particular interest. So far, there is a lack of knowledge about source, behavior, fate, and toxicity of environmental nano- and submicron particles. This article is focused on the separation and characterization methods, which are currently used for their investigation. The application of sedimentation, centrifugation, membrane filtration, and field- and flow-based techniques to the separation of nano- and submicron particles are discussed. The advantages and limitations of the techniques are briefly summarized. Among characterization/analysis methods, a special attention is given to electron microscopy, light scattering as well as atomic absorption spectroscopy, optical emission, and mass spectrometry.
\end{abstract}

Keywords: characterization; environmental; nanoparticles; separation; submicron particles.

\section{Introduction}

Nano- and submicron particles (NP and SMP) exist on the Earth from immemorial time as a result of various natural processes such as volcanic eruptions, dust storms, soil

\footnotetext{
*Corresponding author: Mikhail S. Ermolin, Vernadsky Institute of Geochemistry and Analytical Chemistry, Russian Academy of Sciences, 19 Kosygin Street, Moscow 119991, Russian Federation; and National University of Science and Technology "MISiS", 4 Leninsky Prospect, Moscow 119049, Russian Federation, e-mail: mihail.ermolin@gmail.com.

http://orcid.org/0000-0002-0023-4507

Petr S. Fedotov: Vernadsky Institute of Geochemistry and Analytical Chemistry, Russian Academy of Sciences, 19 Kosygin Street, Moscow 119991, Russian Federation; and National University of Science and Technology “MISiS”, 4 Leninsky Prospect, Moscow 119049, Russian Federation
}

erosion, and fires. It should be noted that according to the recommendations of the International Union of Pure and Applied Chemistry (IUPAC) particles of any shape with dimensions in the range 1-100 $\mathrm{nm}$ are defined as NP, whereas SMP by convention are considered to be in the size range from $100 \mathrm{~nm}$ to $1 \mu \mathrm{m}$. NP and SMP of volcanic ash and dust "travel” around the world entrained by wind and suspended in the atmosphere. Anthropogenic activity also takes an active part in the production of NP and SMP. Industrial processes, traffic emissions, and nanotechnologies are the main sources of anthropogenic NP and SMP. It has been estimated that $10 \%$ of total airborne particulate matter are of anthropogenic origin, whereas $90 \%$ are of natural one (Buzea et al. 2007). Environmental particles may undergo substantial modifications in the chemical and physical properties in course of "aging" processes under natural and anthropogenic conditions (Han and Zender 2010, Kim and Park 2012, Geng et al. 2014). Anthropogenic load on the environment, especially in the form of industrial emissions, may cause considerable change in chemical composition of particulate matter. The impact of such particles on the environment and human health may be very significant. Moreover, airborne particles during their long-range transport affect the Earth energy balance due to the absorbance of sun radiation and scattering it back to space (Houghton 2005, Buzea et al. 2007). Thus, environmental particulate matter may be considered not only in terms of health effects or regional ecological problems but also as a cause of global climate changes.

It is known that airborne particulate matter is an important pathway for exposure of people to environmental pollutants including toxic metals and metalloids. The impact of particles containing toxic metals and metalloids on the environment and human health is strongly dependent on their size and composition. NP and SMP are most hazardous for human health because of their high mobility in the environment. The tiniest fractions of dust or ash particles suspended in the air can easily be transported over long distances and penetrate into respiratory or gastrointestinal tract. Furthermore, specific surface (surface/ mass ratio) of particles and hence their sorption capacity increases with size decreasing that can cause the accumulation of metals and metalloids in finest fractions of dust. Taking into account the aforesaid, environmental 
nanoparticles must be scrutinized because of their extremely high potential sorption capacity for toxic elements, mobility, and penetration ability into the lungs.

Unfortunately, nowadays, there is a lack of knowledge about source, behavior, mobility, fate, and toxicity of environmental NP and SMP. The main reason is the difficulty to recover SMP and NP from environmental samples for further characterization and quantitative analysis. Actually, the problem of characterization of environmental NP and SMP is directly related to the problem of their separation. In fact, NP and SMP in such complex polydisperse environmental samples as dust, volcanic ash, or soil may represent only about thousandths or less of bulk sample (Fedotov et al. 2014). Therefore, their recovery followed by a quantitative determination of analytes is a complex task.

The aim of this article is to review recent advances in field of investigation of NP and SMP (deposited or suspended) of dust, volcanic ash, soil, and water colloids including particle separation methods and techniques for particle characterization and analysis.

\section{Separation of nano- and submicron particles}

There are different fractionation methods based on various principles and covering different size ranges of separated particles (Fedotov et al. 2011). The separation techniques, which are used for the recovery of NP and SMP from volcanic ash, dust, and soil, will be discussed in this section. The presented separation methods can be divided into two groups depending on the phase, where the separation is performed: gaseous or liquid one. However, the latter group of methods is discussed more extensively because of its wide variety as compared to the separation in gaseous media.

\section{Sedimentation methods}

Method of sedimentation in gravitational field is a wellknown technique for microparticles fractionation, conventionally used for the recovery of clay fraction $(<2 \mu \mathrm{m})$ from soils (Guzel and Ibrikci 1994, Ducaroir and Lamy 1995, Gavinelli et al. 1995, Schmidt et al. 1999, Luo et al. 2011, Tsao et al. 2013). The separated clay fractions are usually studied for the trace (Ducaroir and Lamy 1995, Luo et al. 2011) and major (Luo et al. 2011) metals, phosphorus (Guzel and Ibrikci 1994), carbon, and nitrogen (Gavinelli et al. 1995) content. The fraction of particles $<2 \mu \mathrm{m}$ with a certain assumption may be considered as "submicron" fraction. The sedimentation method can also be applied to the investigation of heavy metals association with different particle size fractions (including fraction $<2 \mu \mathrm{m}$ ) of street dust (Acosta et al. 2011). It is evident that this method is suitable for the fractionation of volcanic ash particles. The method is based on differences in sedimentation velocities of particles with different size and density. The time needed for the recovery of fraction is calculated according to the Stokes' law. The separation is achieved by repeated sedimentation and decanting. Often, a dispersing agent (e.g. Na-polyphosphate (Schmidt et al. 1999, Acosta et al. 2011)) is added to the suspension before fractionation to achieve more complete dispersion and prevent the particle agglomeration during time-consuming separation process. In addition, the ultrasonication of suspension for the additional dispersion of the sample under fractionation may be used (Schmidt et al. 1999, Luo et al. 2011, Tsao et al. 2013). On the whole, the method of sedimentation in gravitational field is a time-tested technique, which enables SMP fraction of soil, dust, and volcanic ash to be separated. The main advantage of this method is simplicity because it does not require expensive devices and can be realized in any laboratory. Nevertheless, sedimentation is a time-consuming method, which does not enable NP and SMP fractions to be separated.

Centrifugation is a sedimentation method accelerated by using more intensive g-force. The method enables fractionation time to be decreased. At the same time, the separation of NP and SMP becomes possible. As a time-saving alternative to conventional sedimentation method, conventional (differential) centrifugation is used for the separation of soil particles $<2 \mu \mathrm{m}$ (Stemmer et al. 1998, Novoszad et al. 2007, Ajmone-Marsan et al. 2008, Madrid et al. 2008) and $<1 \mu \mathrm{m}$ (Tang et al. 2009) and studying association of metals with different size fractions (Ajmone-Marsan et al. 2008), their availability and bioaccessibility (Madrid et al. 2008). It is also known that distribution of naphthalene derivatives (Novoszad et al. 2007), organic matter, and enzyme activity (Stemmer et al. 1998) in soils have been studied using a centrifugation. The application of centrifugation to the separation of particles $<450 \mathrm{~nm}$ (Tsao et al. 2013), $<200 \mathrm{~nm}$ (Nishimura et al. 2008), and $<100 \mathrm{~nm}$ (Stemmer et al. 1998, Bakshi et al. 2014) from soils is also reported. The time required for the separation of NP and SMP fractions from soil is also calculated according to the Stokes' equation (Laidlaw and Steinmetz 2005). As a whole, the centrifugation is a universal method for the recovery NP and SMP from polydisperse environmental samples, which 
enables a considerable weight of the sample to be fractionated. However, since the density of particles of one soil may cover a wide range from $<1.9 \mathrm{~g} / \mathrm{cm}^{3}$ (organic particles) up to $>5.0 \mathrm{~g} / \mathrm{cm}^{3}$ (iron oxides), it might be problematic to achieve a precise particle size separation by differential centrifugation for soil suspensions with a high diversity in particle density (Zirkler et al. 2012). It is nearly impossible to achieve an accurate resolution for NP and SMP separation. It should be noted that since NP and SMP represent only about thousandths or less of bulk sample, a considerable sample weight must be handled to separate weight amounts of NP and SMP fractions for their further quantitative analysis. Therefore, due to the cross-contamination of separated fractions, timeconsuming filling and decanting of numerous centrifuge tubes are needed to achieve complete separation with required fraction resolution (Figure 1A).

In addition to differential centrifugation, there is another type of centrifugal techniques for particle separation, which is called density gradient centrifugation. In turn, this technique has two subtechniques: rate-zonal centrifugation and isopycnic centrifugation. In rate-zonal centrifugation, a sample to be separated is added as a thin layer on the top of a density gradient, which is created by layering media of increasing density in a centrifuge tube. The separation is achieved by migration of particles with different rates through the density gradient in the course of centrifugation (Figure 1B). As a result, separated particle fractions appear as zones in the gradient. In contrast to differential centrifugation, this technique enables the separation of particles on the basis of their size, shape, and density without tedious procedure of decanting and filling of centrifugation tubes to achieve the required fraction resolution and avoid cross-contamination of different size fractions.

Nowadays, rate-zonal centrifugation is mainly applied in biological sciences to the separation of cells, organelles, membrane vesicles, viruses, DNA, etc (de Araojo et al. 2008). However, its potential for the fractionation of environmental NP and SMP seems to be promising. The density gradient centrifugation enables the efficient fractionation of 20, 30, 40, 60, 80, 150, $250 \mathrm{~nm}$ gold (Steinigeweg et al. 2011) as well as silver particles (Lee et al. 2014a,b) to be achieved. Thus, the method may be useful for the separation and quantification of engineered NP and SMP in environmental samples.

The isopycnic centrifugation (also known as buoyant or equilibrium separation) enables particles to be fractionated only on the basis of their density (Figure 1C), and therefore will not be described in present review in detail. However, the application of isopycnic centrifugation to the separation of NP and SMP of different origin may be very attractive.

\section{Membrane filtration}

Membrane filtration is a pressure-driven membrane transport process used for the separation of macromolecules, microorganisms, and particles according to their hydrodynamic diameter, which covers a size range from $1 \mathrm{~nm}$ to several micrometers (Fedotov et al. 2011). Membrane filtration is used for the separation and further characterization of soil colloids (Lægdsmand et al. 1999, Worrall et al. 1999, Turner et al. 2004, Klitzke et al. 2008, Tang et al. 2009, Tsao et al. 2013), dust, and volcanic ash NP and SMP (Tepe and Bau 2014, Hofman et al. 2014, Kadar et al. 2014a,b). Membranes with pore diameter of $1 \mathrm{~nm}$ (Turner et al. 2004, Tsao et al. 2013), $50 \mathrm{~nm}$ (Kadar et al. 2014a,b), $100 \mathrm{~nm}$ (Turner et al. 2004, Tang et al. 2009), $200 \mathrm{~nm}$ (Turner et al. 2004, Hofman et al. 2014, Kadar et al. 2014a,b), $450 \mathrm{~nm}$ (Worrall et al. 1999, Tepe and Bau 2014, Kadar et al. 2014a,b), $1 \mu \mathrm{m}$ (Turner et al. 2004), and $3 \mu \mathrm{m}$ (Hofman et al. 2014) are used for the separation of environmental particles in liquid media. Membrane filtration
A

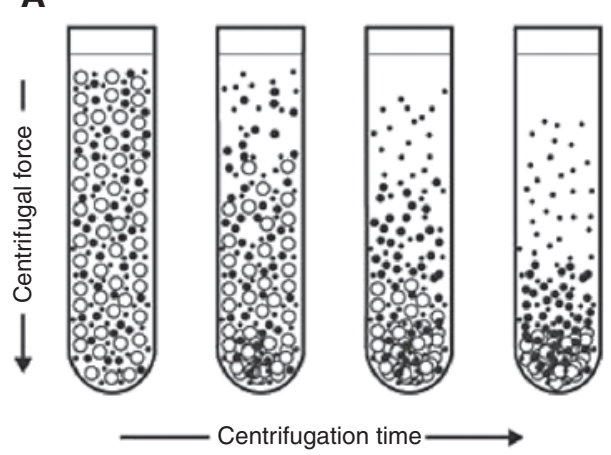

B

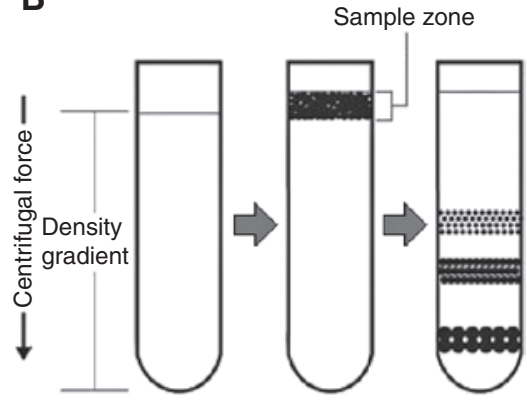

C

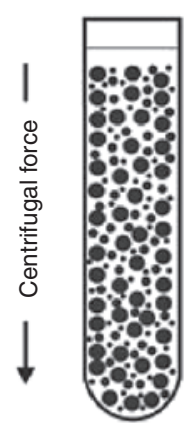

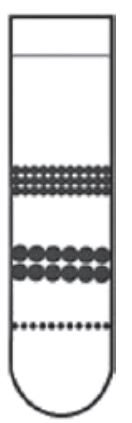

Figure 1: The principle of differential (A), rate-zonal (B), and isopycnic (C) centrifugation. 
is often used after the preseparation by the conventional sedimentation or centrifugation to remove the coarse particles before filtering (Tang et al. 2009, Tsao et al. 2013). In general, membrane filtration is a complex process and the results of filtration may be distorted due to the filter cake formation and clogging of membrane pores (Fedotov et al. 2011, Zirkler et al. 2012). For example, it has been demonstrated that the recoveries of kaolinite particles (100-300 nm) filtered through membranes with pore sizes 200, 400, and $800 \mathrm{~nm}$ were only 10, 50, and 85\%, respectively (Karube et al. 1996). The cross-flow filtration (or tangential flow filtration) enables these artifacts to be minimized (Tang et al. 2009, Fedotov et al. 2011). However, cross-flow filtration is applicable only to relatively low colloid concentration suspensions. Moreover, the comparative study on separation of $<1 \mu \mathrm{m}$ soil particle fraction showed that membrane filtration underestimates the concentration of colloids that is partly attributed to the formation of filter cakes but mainly results from pores clogging (Zirkler et al. 2012). This corresponds to findings of Gimbert et al. (Gimbert et al. 2005) who compared filtration and centrifugation techniques to isolate two colloidal fractions of soil suspensions ( $<450$ and $<200 \mathrm{~nm}$ ). Membrane filtration seriously underestimated the total mass of particulate matter in suspensions as compared to centrifugation. It should be noted that membrane filtration results are also dependent on the membrane material (cellulose nitrate, glass fiber, polycarbonate, etc.) (Zirkler et al. 2012). On the other hand, as has been mentioned earlier, centrifugation is unfavorable for soil suspensions with a high range of density of particles for precise size separation. Among the advantages of membrane filtration, the possibility of handling large volumes of sample up to 1 $\mathrm{m}^{3}$ can be highlighted (Fedotov et al. 2011). It is useful for the preconcentration, separation, and characterization of diluted suspensions of environmental particulate matter. Another advantage of membrane filtration is the possibility to interpret the results of separation of particles and macromolecules without using size reference materials because the membrane pore diameters themselves can serve as size standards (Fedotov et al. 2011).

\section{Field-and flow-based methods}

Field- and flow-based techniques are widely used for the separation and characterization of particulate matter of different origin, including environmental NP and SMP (Fedotov et al. 2011).

Field-flow fractionation (FFF) is a particle separation and sizing method. FFF is a relatively young technique, despite the fact that general concept of FFF was developed in 1960s (Giddings 1966, Fedotov et al. 2011). FFF is a set of liquid chromatography-like elution methods. However, unlike chromatography, FFF requires no stationary phase and only physical interactions are involved in the separation process (Schimpf et al. 2000, Fedotov et al. 2011,). The separation is achieved under the action of the nonuniform flow velocity profile of a carrier fluid and a physical force field (gravitational, centrifugal, electric, magnetic, etc.) applied at a right angle to the thin $(0.05-0.5-\mathrm{mm})$ ribbonlike channel (Fedotov et al. 2011) (Figure 2). According to the nature of cross-field force, several FFF subtechniques are differentiated: sedimentation FFF (SdFFF), flow FFF (FlFFF), etc (Fedotov et al. 2011). The SdFFF is performed in a circular flat channel inserted inside a centrifugal basket. In FlFFF, the cross-flow play the role of external force field. In assymetrical FlFFF (also called AF4), the most commonly used FlFFF type, one channel wall (accumulation wall) is permeable for carrier-fluid, which passing through it form the cross-flow. Without going into details of FlFFF classification, further we will refer to these methods just as FlFFF.

FFF is a powerful analytical tool for the separation and characterization of environmental macromolecules and particles (Beckett 1991). It was demonstrated that SdFFF can be successively used for the fractionation and characterization of some inorganic colloidal particles and

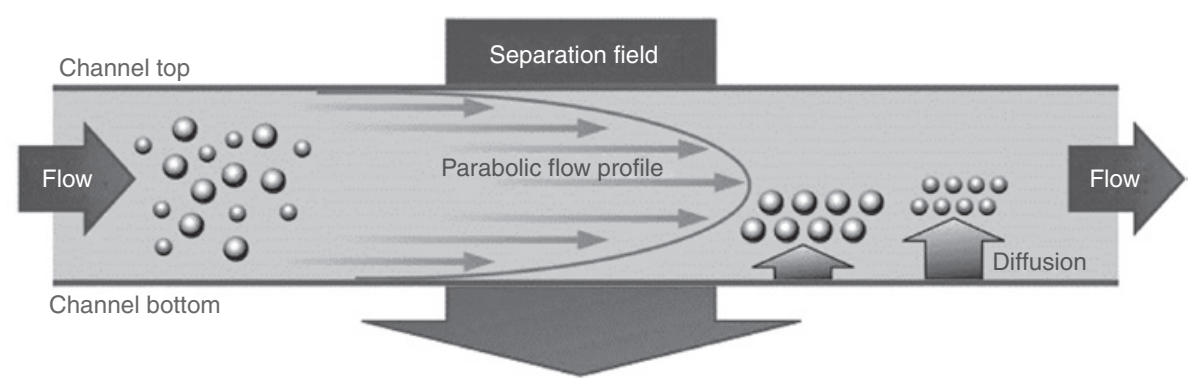

Figure 2: The principle of field-flow fractionation technique. 
river-borne suspended particulate matter of size range $<1 \mu \mathrm{m}$ (Taylor et al. 1992, Murphy et al. 1993, Contado et al. 1997), soil colloids of size $<1-2 \mu \mathrm{m}$ (Chittleborough et al. 1992, Ranville et al. 1999), and colloidal kaolin particles (Blo et al. 1995). SdFFF is also was applied to the study of mercury association with soil colloids within size range 0.1-1 $\mu \mathrm{m}$ (Santoro et al. 2012). Nowadays, SdFFF can be used for the separation of particles $>10 \mathrm{~nm}$. This limitation is related to capability of centrifuges, which are used for cross-field force generation. This restriction can be avoided by using another FFF subtechnique, FlFFF, which enables particles down to $1 \mathrm{~nm}$ to be fractionated. FlFFF is used for the fractionation and characterization of water (v.d. Kammer and Forstner 1998, Hassellov et al. 1999, Lyven et al. 2003) and soil (Baalousha et al. 2006) colloids. FlFFF has been applied to the fractionation of soil nanocolloids for studying iron (Regelink et al. 2013b, 2014), phosphorus (Regelink et al. 2013a), uranium (Claveranne-Lamolère et al. 2009, 2011, Brittain et al. 2012), and to trace metals (Brittain et al. 2012) speciation. FFF is used for the separation, detection, and quantification of such engineered NP as silver (Koopmans et al. 2015), multiwalled carbon nanotubes (Gogos et al. 2014), ZnO (Gimbert et al. 2007) in soils. For fractionation and characterization of soil colloids by FFF, a preseparation step is required. As a rule, centrifugation and/ or membrane filtration (Claveranne-Lamolère et al. 2009, 2011, Santoro et al. 2012, Koopmans et al. 2015) as well as conventional sedimentation (Gimbert et al. 2008) are used for sample treatment before FFF procedure. Sample treatment plays an important role in further fractionation and characterization of soil NP and SMP. For example, as has been mentioned earlier, membrane filtration can seriously underestimate the colloidal fraction in soil sample (Gimbert et al. 2005, 2006) that can distort FFF results.

Generally, FFF is a powerful analytical tool for separation and characterization of environmental SMP and NP in size down to $\sim 1 \mathrm{~nm}$. Besides, FFF systems can be coupled on-line to different specific detectors to provide a comprehensive information about sample under investigation. However, the main limitation of this technique is weight of handling sample, which is about $1 \mathrm{mg}$ and related to the volume of separation channel of FFF system. This requires an increased sensitivity of detection techniques used for the analysis of separated fractions. Besides, samples should be highly homogenized in order to provide representative data (Fedotov et al. 2011). However, in FFF studies of NP and SMP of dry particulate samples (e.g. soils), a preseparation step is used, as a rule, to recover fine particles. Since the weight of initial sample (taken, for example, for the preseparation by membrane filtration or centrifugation) is on a gram level, the data obtained in such a way may be considered as representative ones.

The fractionation in a rotating coiled column (RCC), which can be attributed to nonconventional FFF, enables the loading sample weight to be increased up to at least $1 \mathrm{~g}$ (Fedotov et al. 2011, 2015). This technique, named coiled tube FFF (CTFFF), employs the complex asymmetrical force field generated in planetary centrifuges. Among the other FFF techniques, CTFFF is more similar to SdFFF utilizing a circular channel inserted inside a centrifugal basket. Though both SdFFF and CTFFF are based on the centrifugal force field, there are two important differences between these techniques. Firstly, in the case of CTFFF, the mixture to be separated is not introduced into a thin channel but pumped with the carrier fluid through a long rotating coiled column (inner capacity about $20 \mathrm{ml}$ or more). Secondly, in the planetary centrifuge used for performing CTFFF, particles and fluid in the coiled column are under the action of the complex asymmetrical centrifugal force field since the column drum rotates around its own axis and at the same time revolves around the central axis of the centrifuge. The separation of NP and SMP fractions is achieved by an increasing step gradient of the carrier fluid flow rate at a constant column rotational speed (Fedotov et al. 2015).

FFF in RCC has been successfully applied to the separation of soil clay fraction $(<2 \mu \mathrm{m})$ for further characterization and analysis (Katasonova et al. 2005). Fractionation in rotating coiled columns may be considered as a timesaving alternative to the conventional sedimentation in the gravitational field. It is also known about using of RCC for the separation of NP and SMP $(<0.3$ and 0.3-1.0 $\mu \mathrm{m})$ of street dust samples for studying trace metals ( $\mathrm{Cr}$, $\mathrm{Ni}, \mathrm{Cu}, \mathrm{Cd}, \mathrm{Zn}, \mathrm{Sn}$, and $\mathrm{Pb}$ ) and rare-earth elements (La, $\mathrm{Ce}, \mathrm{Pr}, \mathrm{Nd}$, and $\mathrm{Sm}$ ) association with different size particle fractions (Fedotov et al. 2014). CTFFF was also applied to the fractionation of volcanic ash samples. As a result, the fractions of nano-, submicron, and micron volcanic ash particles were separated (Fedotov et al. 2015). FFF in RCC is a new but promising technique for the separation and characterization of nano- and microparticles (Fedotov et al. 2015).

Another field- and flow-based technique, which is used for NP and SMP particle separation, is continuousflow centrifugation (Zhang et al. 2013). This method enables large volumes of material to be separated without time-consuming filling and decanting of numerous centrifuge tubes. Continuous-flow centrifuges are used for implementation of this technique. The particle suspension is pumped with high flow rate into the rotor of centrifuge for separation. The different size fraction can be separated 
by controlling the rotor speed. Thus, application of continuous-flow centrifugation to the recovery of $<0.2,<0.6$, and $<1 \mu \mathrm{m}$ particle fractions from soils is reported (Zhang et al. 2013).

\section{Separation in impactors}

Separation of particles in gaseous media is often used for the characterization of size distribution and chemical composition of airborne particulate matter. Different multistage (cascade) impactors are used for the study of endotoxins (Traversi et al. 2011), polycyclic aromatic hydrocarbons (Hata et al. 2013), polychlorinated dibenzo$p$-dioxins and dibenzofurans (Yu et al. 2009), soluble iron (Ooki et al. 2009), vanadium, iron, arsenic, and lead (Tolocka et al. 2004) concentrations in different NP and SMP fractions of dust. It is also known about application of impactors for the investigation of chemical composition of dust (Reid et al. 2003, Geng et al. 2014) and volcanic ash (Ivleva et al. 2013) aerosol particles. It is reported of using impactors for the separation and collection of airborne particles in size classes of $<0.49,0.49-0.95 \mu \mathrm{m}$ (Traversi et al. 2011), <0.45, 0.45-0.65, and 0.65-1.1 $\mu \mathrm{m}$ (Ooki et al. 2009); <0.07, 0.07-0.5, and 0.5-1.0 $\mu \mathrm{m}$ (Hata et al. 2013), <0.09, 0.09-0.24, 0.24-0.34, 0.34-0.56, 0.56-0.74, and $0.74-1.1 \mu \mathrm{m}$ (Reid et al. 2003); <0.25, 0.25-0.5, and $0.5-1 \mu \mathrm{m}$ (Geng et al. 2014). The separation in this case is achieved by pumping of large air volumes through impactors and occurred according to the aerodynamic diameter of particles. It should be noted that particle separation in gaseous media according to their aerodynamic diameter is possible not only for aerosol particulate matter but also for deposited one. There are special laboratory chambers (Ho et al. 2003, Chow et al. 2004, Zhao et al. 2006) as well as mobile devices (Jancsek-Turóczi et al. 2013) for the resuspension, separation, and further characterization of dust particles.

Techniques currently used for the separation of environmental NP and SMP are briefly summarized in Table 1.

\section{Characterization and analysis of nano- and submicron particles}

\section{Particle size distribution}

Size distribution of particles is an important characteristic of environmental samples, which determines their properties. Different methods are used for the assessment of particle size and size distribution: scanning electron microscopy (SEM), environmental SEM (ESEM), atmospheric SEM (ASEM), transmission electron microscopy (TEM), laser diffraction (LD, also known as static light scattering), multiangle laser light scattering (MALLS), and dynamic light scattering (DLS, also known as photon correlation spectroscopy). Scanning (Reid et al. 2003, Tang et al. 2009, Acosta et al. 2011, Geng et al. 2014, Kadar et al. 2014a,b) and transmission (Tang et al. 2009, Tsao et al. 2013, Zhang et al. 2013, Kadar et al. 2014a,b) electron microscopies are the mostly used techniques for studying the size and morphology of environmental particles. Electron microscopy techniques enable the particle size to be measured precisely. However, an adequate particle size distribution is difficult to obtain due to small sample size. One of the disadvantages of methods such as SEM and TEM is a difficulty of specimen preparation, which may affect the structures to be analyzed. Charging effects (in SEM) occurring in nonconducting samples (e.g. soils) under high vacuum also may hinder the imaging (Tuoriniemi et al. 2014). Moreover, vacuum environment inside the SEM or TEM chamber requires the samples to be prepared in a dry state. Some artifacts can be introduced in the course of drying process that can lead to incorrect results (Luo et al. 2013). ESEM and ASEM, where it is possible to have a higher pressure (including atmospheric pressure) in the sample chamber than in a conventional SEM instrument, may be suitable instruments for characterization of complex environmental particulate samples (Tuoriniemi et al. 2014). In contrast to SEM and TEM, ESEM and ASEM offer imaging of dry, semi-dry, and liquid samples in their original state and provide a broad overview of the whole population of NP and SMP (Luo et al. 2013). For example, using ESEM and ASEM for the in situ characterization of engineered NP and SMP in soil (Tuoriniemi et al. 2014) and natural sediment (Luo et al. 2013) has been reported.

Methods such as LD, MALLS, and DLS allow one to estimate particle size distribution in suspension. In general, LD and MALLS are the methods based on one measurement principle. Thus, in LD analysis, according to Fraunhofer diffraction theory, the intensity of light scattered by a particles is directly proportional to their size and the angle of the scattered laser beam increases as particle size decreases (and vice versa). It should be clarified that simultaneous measurements at several angles are known as MALLS. LD techniques are used for the measurement of particle size in nano-, submicron, and micron range. In turn, DLS is based on another measurement principle of particle size and size distribution. The Brownian motion of different size particles in suspension causes the 


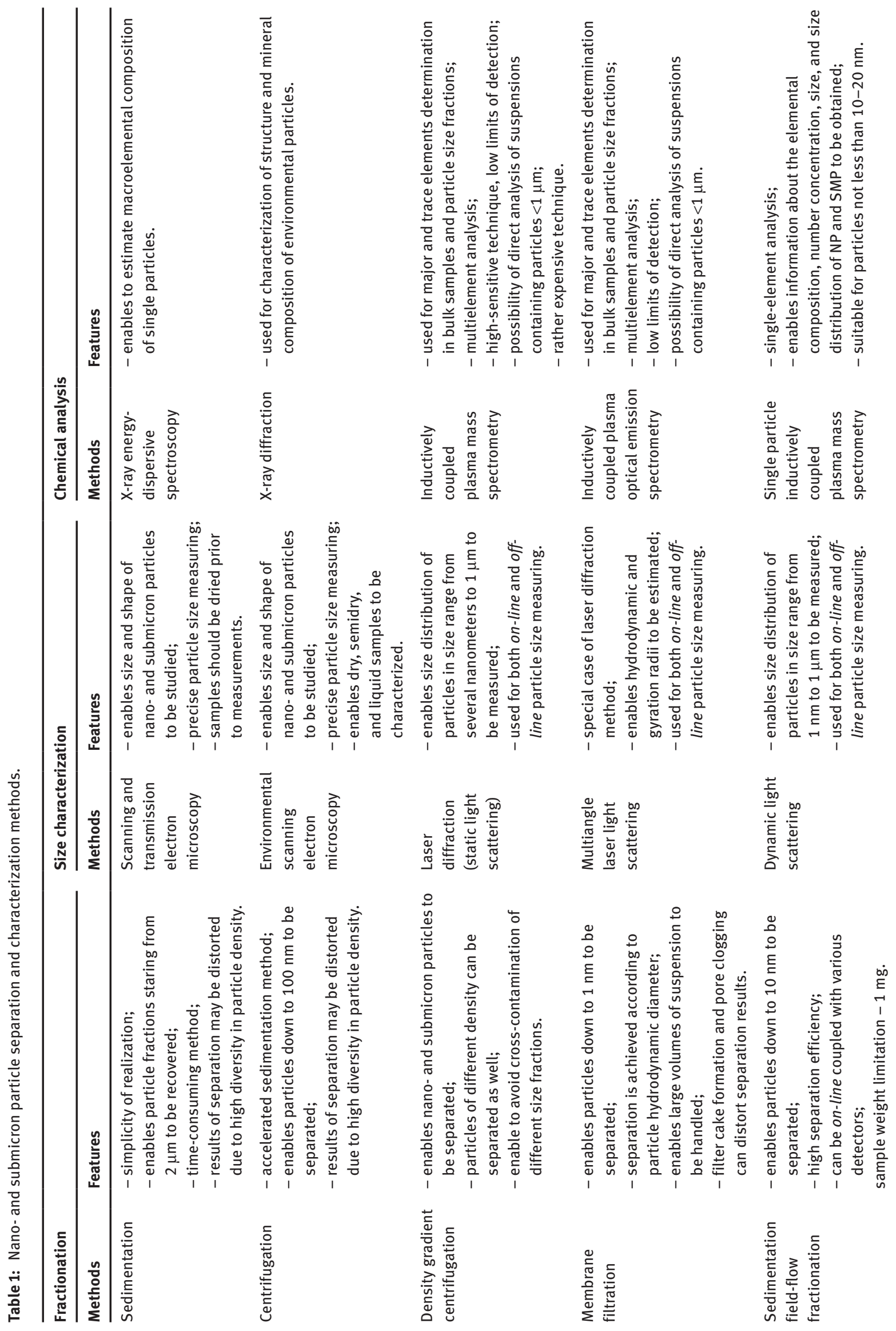




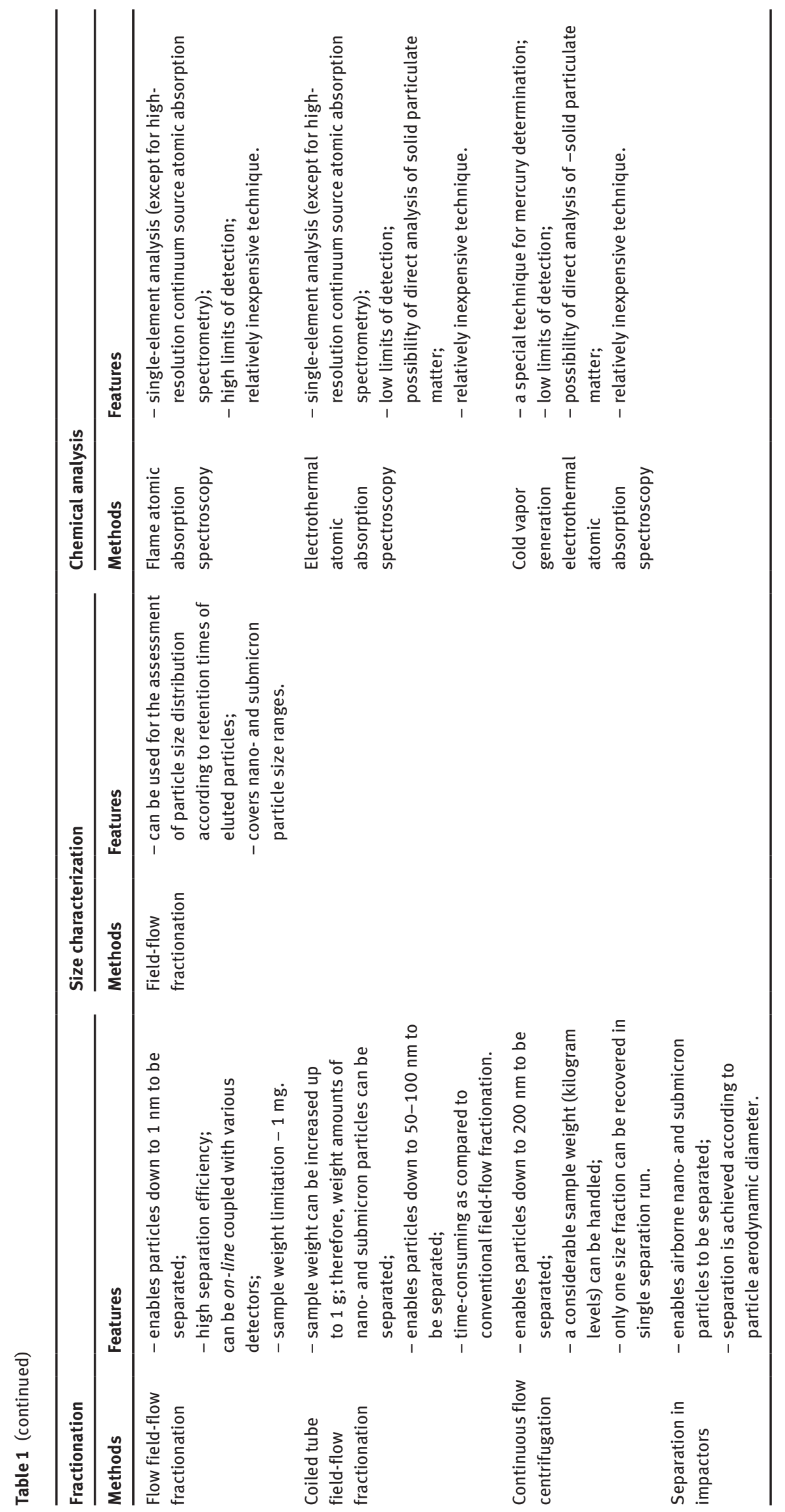


scattering of laser light with different intensities. Analysis of these intensity fluctuations provides the information about velocity of the Brownian motion and hence the particle size using the Stokes-Einstein relationship. DLS is commonly used for the characterization of particles in nano- and submicron scale.

Thus, LD (Tang et al. 2009, Zhang et al. 2013), DLS (Bakshi et al. 2014, Kadar et al. 2014a,b), and MALLS (Andersson et al. 2003, Claveranne-Lamolère et al. 2009, 2011, Gogos et al. 2014) are used for the measurement of particle size distribution and for the evaluation of hydrodynamic and gyration radii of macromolecules and particles. Aforementioned light scattering techniques may be used in both off-line and on-line modes. The main features of particle size characterization techniques are summarized in Table 1.

It should be noted that FFF techniques also enable particle size distribution of the sample to be estimated. Particles of different size have different retention time in the course of FFF procedure. Thus, calibration of FFF by using standard particles (e.g. polystyrene) allows one to evaluate the size distribution of NP and SMP in soil and other samples (Claveranne-Lamolère et al. 2009, 2011).

\section{Chemical composition}

For chemical characterization (assessment of elemental and mineral composition) of environmental NP and SMP, a wide range of analytical techniques is employed.

Electron microscopes (SEM or TEM) equipped with energy-dispersive X-ray spectroscopy detectors (EDS) can be used not only for size and morphology characterization of particles but also to estimate particle macroelemental composition (Reid et al. 2003, Acosta et al. 2011, Geng et al. 2014, Kadar et al. 2014a,b). It should be noted that SEM-EDS enables single particles including nanoparticles to be analyzed without separation (Shi et al. 2009, Dalmora et al. 2016). However, this is a semiquantitative method, which allows one to determine mainly major elements. Moreover, representativity in single-particle analysis by SEM-EDS is very poor because of variety of particle origin, age, and hence chemical composition. This is why estimation of chemical composition of particular size fraction is in general a difficult task.

$\mathrm{X}$-ray diffraction (XRD) is used for characterization of structure and mineral composition of environmental particles. Application of conventional and synchrotron XRD to characterization of clay minerals composition in various particle size fractions (1-100, 100-450, and 450$2000 \mathrm{~nm}$ ) of soils has been reported (Tsao et al. 2013). XRD was also used for the identification of clay minerals in $<0.2$ and 0.2-3 $\mu \mathrm{m}$ soil particles (Zhang et al. 2013). In addition to XRD, Raman microspectroscopy is also utilized to study mineral composition and structure of individual volcanic ash particles for their identification (Ivleva et al. 2013). Characterization of particle structure may be used for identification of their origin, for example, volcanic eruptions or soil erosion, and aging (Ivleva et al. 2013).

Advanced analytical techniques are utilized for the investigation of elemental composition of environmental NP and SMP. Such techniques as inductively coupled plasma optical emission spectrometry (ICP-OES) (Tang et al. 2009, Luo et al. 2011, Zhang et al. 2013, Fedotov et al. 2014), inductively coupled plasma mass spectrometry (ICP-MS) (Tang et al. 2009, Luo et al. 2011, Fedotov et al. 2014, Tepe and Bau 2014), and atomic absorption spectroscopy (AAS) (Ajmone-Marsan et al. 2008, Madrid et al. 2008, Acosta et al. 2011) are often utilized for off-line determination of major ( $\mathrm{K}, \mathrm{Na}, \mathrm{Al}, \mathrm{Ca}, \mathrm{Fe}, \mathrm{Mg}$, etc.) and trace $(\mathrm{Cu}, \mathrm{Zn}, \mathrm{Pb}, \mathrm{Co}, \mathrm{Ni}, \mathrm{Cr}$, Cd, etc.) elements in NP and SMP fractions of soil, dust, and volcanic ash after their acid digestion. The application of cold vapor generation electrothermal atomic absorption spectrometer (CV-ETAAS) to the investigation of mercury association with soil NP and SMP is also known (Santoro et al. 2012). As a rule, off-line determination of element concentrations is applied to NP and SMP fractions separated by using sedimentation, centrifugation, and membrane filtration techniques.

Special attention should be paid to the method called single particle-ICP-MS (SP-ICP-MS), which enable measurements on a "particle by particle" basis to be performed (Laborda et al. 2014). This technique, initially being proposed for the characterization of aerosol particles (Nomizu et al. 1993), was applied to analysis of colloidal suspensions on uranium (Degueldre et al. 2006a), zirconia (Degueldre et al. 2004), thorium (Degueldre and Favarger 2004), and gold (Degueldre et al. 2006b). In recent years, due to development on nanotechnologies and hence the necessity to establish new techniques for characterization and quantification of engineered NP, SP-ICP-MS has received renewal interest (Heithmar and Pergantis 2010, Pace et al. 2011). SP-ICP-MS enables information about the elemental composition, number concentration, size, and size distribution of NP and SMP to be obtained. The principle of particle characterization by SP-ICP-MS is based on assumption that each recorded pulse represents a single particle from which it follows: (i) the frequency of the pulses is directly related to the number concentration of particles and (ii) intensity of each pulse is proportional to the mass of element in each detected particle (i.e. its size) (Laborda et al. 2014). 
It should be noted that dissolved forms of the nanoparticle constituent elements can be determined as well. Soluble forms of an element are distributed homogenously within a solution; therefore, the mass of element entering the plasma per unit of time and traveling to the detector as ions can be considered constant, producing a "steady" signal (Laborda et al. 2014). By contrast, if the sample contains NP, the element is no longer distributed homogenously and present as discrete groups of atoms (Laborda et al. 2014).

Thus, it is known about the application of SP-ICP-MS to the quantification and characterization of engineered copper NP in soil (Navratilova et al. 2015), titanium dioxide, silver, and gold NP (Donovan et al. 2016a, Yang et al. 2016) as well as zinc oxide and cerium dioxide NP (Donovan et al. 2016b) in water. It is also reported that combination of SP-ICP-MS with synchrotron-based X-ray absorption spectroscopy enables the release of colloidal arsenic in environmental samples to be evaluated (GomezGonzalez et al. 2016).

SP-ICP-MS is a promising sizing and quantification technique for environmental NP and SMP; however, some limitations should be mentioned. First of all, to provide precise information about size of the particles, their composition, density, and shape must be known (Laborda et al. 2014). Therefore, the combination of SP-ICP-MS with imaging techniques (e.g. electron or atomic force microscopy) is recommended. Secondly, the method is suitable for particles not less than 10-20 nm (depending on the constituent element) (Laborda et al. 2014, Lee et al. 2014a,b). The detection of smaller sized NP involves the use of ICP-MS instruments with a higher detection efficiency (Laborda et al. 2014).

In general, combination of aforementioned off-line analytical techniques may give a comprehensive information about size, morphology, structure, and chemical composition of environmental NP and SMP. However, in recent years, hyphenated techniques have received an increased attention as powerful analytical tool for on-line separation and characterization/analysis of complex samples. Hyphenated techniques enable time and additional errors related to sample handling in interstitial stages of characterization and analysis to be reduced.

As it has been mentioned earlier, FFF is a good basis for developing different "hyphenated" techniques for separation, investigation, and analysis of environmental colloidal and particulate matter (Fedotov et al. 2011). It can be easily coupled to various detectors such as ultraviolet (UV), differential refractive index, MALLS, fluorescence, ICP-MS, and ICP-OES. As a rule, UV-detector and MALLS are always used for detection of particles and their size measurement. For chemical analysis, different techniques are employed. For example, coupling of SdFFF with ICP-MS (Murphy et al. 1993, Ranville et al. 1999) and ETAAS (Contado et al. 1997) has been proposed for environmental nanocolloid characterization. The hyphenation of FlFFF with ICP-MS (v.d. Kammer and Forstner 1998, Hassellov et al. 1999, Lyven et al. 2003, Claveranne-Lamolère et al. 2009, 2011) and ICP-OES (Sangsawong et al. 2011) is also reported. It is also known about hyphenation of FlFFF with SP-ICP-MS for the detection and quantification of silver nanoparticles in aquatic systems at environmentally relevant concentrations (Huynh et al. 2016). It should be noted that coupling of FFF-system with detector (i.e. ICP-MS, ICP-OES, etc) lead to the analysis of particle suspension. In this case, the results are directly dependent on completeness of particle decomposition. It is known that in major cases particles $<1 \mu \mathrm{m}$ fully decompose in electrothermal atomizer or ICP (Olesik and Gray 2012). Therefore, direct analysis of NP and SMP by using ICP-MS, ICP-OES, and ETAAS may be considered to be reliable.

\section{Quality control of separation and characterization methods}

The problem of quality control of separation and characterization methods of NP and SMP is very important within the context of reliability of obtained data because, for today, there are no reference materials of NP and SMP for complex environmental samples such as soil, dust, and ash. It is a relevant subject, which should help in comparison and interpretation of analytical results. Some aspects of this problem will be discussed in this section.

With regard to the separation methods, the quality control may be implemented by imaging (e.g. SEM and TEM) and light scattering (LD, DLS) techniques. In this respect, imaging techniques seem to be more reliable because they can get more precise information about size, shape, and morphology of separated particles. The measurement of particle size by light scattering techniques is based on certain theories that have certain assumptions, which may introduce some artifacts in acquired data (especially when investigating environmental particles with complex composition and shape). Therefore, ideally, particle size distribution obtained by light scattering techniques should by confirmed by electron microscopy. In this sense, among separation techniques, $\mathrm{FFF}$ is more self-sustained because it is a sizing technique as well. However, sizing theory of FFF also has some assumptions 
(e.g. particle sphericity); therefore, results obtained should be confirmed by aforementioned light scattering and imaging techniques.

Membrane methods should also be mentioned in terms of quality control of separation. Pore diameter of membrane is considered to be a size standard for particles permeating through the membrane. However, when using cascade filtration, the possibility of cross-contamination of separated fractions may be very significant because of some negative side processes. In turn, one-stage membrane separation enables particles less than membrane pore diameter to be recovered in permeate. Similar to other separation methods, results obtained should be confirmed by light scattering and imaging techniques. In respect to quality control, particle separation in impactors according to aerodynamic diameter is similar to membrane filtration (according to hydrodynamic diameter). The diameter of orifices used in impactors may be considered as a size standard as well.

As has been mentioned, there are no reference materials of NP and SMP for complex environmental samples such as soil, dust, and ash. Therefore, concerning the quality control of elemental analysis, only calibration of analytical instrument by using elemental standards is appropriate.

\section{Conclusion}

It can be concluded that all considered separation and characterization techniques, which are used for investigation of environmental NP and SMP, have both advantages and limitations. The selection of appropriate technique is dependent on the research tasks related to the nature and physicochemical properties of particulate samples, size of particles to be separated, elements under study, or expensiveness and availability of analytical devices. The features of different separation and characterization/analysis techniques are briefly displayed in Table 1 . In most cases, a reasonable combination of separation and characterization techniques allows one to obtain the most reliable and comprehensive results. Special emphasis should be given to hyphenated techniques, which enables separation and characterization/analysis of environmental NP and SMP to be performed on-line.

Acknowledgments: The authors would like to acknowledge the financial support from the Ministry of Education and Science of the Russian Federation (Program of Increasing Competitiveness of NUST "MISiS", project
No K2-2015-072) and the Russian Foundation of Basic Research (project No 14-03-00128).

\section{References}

Acosta, J.; Faz, A.; Kalbitz, K.; Jansen, B.; Martinez-Martinez, S. Heavy metal concentrations in particle size fractions from street dust of Murcia (Spain) as the basis for risk assessment. J. Environ. Monit. 2011, 13, 3087-3096.

Ajmone-Marsan, F.; Biasioli, M.; Kralj, T.; Grcman, H.; Davidson, C.; Hursthouse, A.; Madrid, L.; Rodrigues, S. Metals in particle-size fractions of the soils of five European cities. Environ. Pollut. 2008, 152, 73-81.

Andersson, M.; Wittgren, B.; Wahlund, K. G. Accuracy in multiangle light scattering measurements for molar mass and radius estimations. Model calculations and experiments. Anal. Chem. 2003, 75, 4279-4291.

Baalousha, M.; Kammer, F. V. D.; Motelica-Heino, M.; Hilal, H. S.; Le Coustumer, P. Size fractionation and characterization of natural colloids by flow-field flow fractionation coupled to multi-angle laser light scattering. J. Chromatogr. A. 2006, 1104, 272-281.

Bakshi, S.; He, Z.; Harris, W. A new method for separation, characterization, and quantification of natural nanoparticles from soils. J. Nanopart. Res. 2014, 16, 2261-2271.

Beckett, R. Field-flow fractionation-ICP-MS: a powerful new analytical tool for characterizing macromolecules and particles. At. Spectrosc. 1991, 12, 215-246.

Blo, G.; Contado, C.; Fagioli, F.; Bollain Rodriguez, M. H.; Dondi, F. Analysis of kaolin by sedimentation field-flow fractionation and electrothermal atomic absorption spectrometry detection. Chromatographia. 1995, 41, 715-721.

Brittain, S. R.; Cox, A. G.; Tomos, A. D.; Paterson, E.; Siripinyanond, A.; McLeod, C. W. Chemical speciation studies on DU contaminated soils using flow field flow fractionation linked to inductively coupled plasma mass spectrometry (FIFFF-ICP-MS). J Environ Monit. 2012, 14, 782-790.

Buzea, C.; Pacheco Blandino, I.; Robbie, K. Nanomaterials and nanoparticles: sources and toxicity. Biointerphases. 2007, 2, MR17-MR172.

Chittleborough, D. J.; Hotchin, D. M.; Beckett, R. Sedimentation field-flow fractionation: a new technique for the fractionation of soil colloids. Soil Sci. 1992, 153, 341-348.

Chow, J. C.; Watson, J. G.; Kuhns, H.; Etyemezian, V.; Lowenthal, D. H.; Crow, D.; Kohl, S. D.; Engelbrecht, J. P.; Green, M. C. Source profiles for industrial, mobile, and area sources in the Big Bend Regional Aerosol Visibility and Observational study. Chemosphere. 2004, 54, 185-208.

Claveranne-Lamolère, C.; Lespes, G.; Dubascoux, S.; Aupiais, J.; Pointurier, F.; Potin-Gautier, M. Colloidal transport of uranium in soil: size fractionation and characterization by field-flow fractionation-multi-detection. J. Chromatogr. A. 2009, 1216, 9113-9119.

Claveranne-Lamolère, C.; Aupiais, J.; Lespes, G.; Frayret, J.; Pili, E.; Pointurier, F.; Potin-Gautier, M. Investigation of uraniumcolloid interactions in soil by dual field-flow fractionation/ capillary electrophoresis hyphenated with inductively coupled plasma-mass spectrometry. Talanta. 2011, 85, 2504-2510. 
Contado, C.; Blo, G.; Fagioli, F.; Dondi, F.; Beckett, R. Characterisation of River Po particles by sedimentation field-flow fractionation coupled to GFAAS and ICP-MS. Colloids Surf., A. 1997, 120, 47-59.

Dalmora, A. C.; Ramos, C. G.; Oliveira, M. L. S.; Teixeira, E. C.; Kautzmann, R. M.; Taffarel, S. R.; de Brum, I. A. S.; Silva, L. F. O. Chemical characterization, nano-particle mineralogy and particle size distribution of basalt dust wastes. Sci. Total Environ. 2016, 539, 560-565.

de Araojo, M. E. G.; Huber, L. A.; Stasyk, T. Isolation of endocitic organelles by density gradient centrifugation. Methods Mol. Biol. 2008, 424, 317-331.

Degueldre, C.; Favarger, P. Y. Thorium colloid analysis by single particle inductively coupled plasma-mass spectrometry. Talanta. 2004, 62, 1051-1054.

Degueldre, C.; Favarger, P. Y.; Bitea, C. Zirconia colloid analysis by single particle inductively coupled plasma-mass spectrometry. Anal. Chim. Acta. 2004, 518, 137-142.

Degueldre, C.; Favarger, P.-Y.; Rosse', R.; Wold, S. Uranium colloid analysis by single particle inductively coupled plasma-mass spectrometry. Talanta. 2006a, 68, 623-628.

Degueldre, C.; Favarger, P. Y.; Wold, S. Gold colloid analysis by inductively coupled plasma-mass spectrometry in a single particle mode. Anal. Chim. Acta. 2006b, 555, 263-268.

Donovan, A. R.; Adams, C. D.; Ma, Y.; Stephan, C.; Eichholz. T.; Shi, $\mathrm{H}$. Single particle ICP-MS characterization of titanium dioxide, silver, and gold nanoparticles during drinking water treatment. Chemosphere. 2016a, 144, 148-153.

Donovan, A. R.; Adams, C. D.; Ma, Y.; Stephan, C.; Eichholz. T.; Shi, $H$. Detection of zinc oxide and cerium dioxide nanoparticles during drinking water treatment by rapid single particle ICP-MS methods. Anal. Bioanal. Chem. 2016b, 408, 5137-5145.

Ducaroir, J.; Lamy, I. Evidence of trace-metal association with soil organic-matter using particle-size fractionation after physical dispersion treatment. Analyst. 1995, 120, 741-745.

Fedotov, P. S.; Vanifatova, N. G.; Shkinev, V. M.; Spivakov, B.Ya. Fractionation and characterization of nano- and microparticles in liquid media. Anal. Bioanal. Chem. 2011, 400, 1787-1804.

Fedotov, P. S.; Ermolin, M. S.; Karandashev, V. K.; Ladonin, D. V. Characterization of size, morphology and elemental composition of nano-, submicron, and micron particles of street dust separated using field-flow fractionation in a rotating coiled column. Talanta. 2014, 130, 1-7.

Fedotov, P. S.; Ermolin, M. S.; Katasonova, O. N. Field-flow fractionation of nano- and microparticles in rotating coiled columns. J. Chromatogr. A. 2015, 1381, 202-209.

Gavinelli, E.; Feller, C.; Larré-Larrouy, M.; Bacye, B.; Djegui, N.; Nzila, J. A routine method to study soil organic matter by particle-size fractionation: examples for tropical soils. Commun. Soil Sci. Plant Anal. 1995, 26, 1749-1760.

Geng, H.; Hwang, H.; Liu, X.; Dong, S.; Ro, C.-U. Investigation of aged aerosols in size-resolved Asian dust storm particles transported from Beijing, China, to Incheon, Korea, using low-Z particle EPMA. Atmos. Chem. Phys. 2014, 14, 3307-3323.

Giddings J. C. A new separation concept based on a coupling of concentration and flow nonuniformities. Sep. Sci. 1966, 1, $123-125$.

Gimbert, L. J.; Haygarth, P. M.; Beckett, R.; Worsfold, P. J. Comparison of centrifugation and filtration techniques for the size fractionation of colloidal material in soil suspensions using sedimentation field-flow fractionation. Environ. Sci. Technol. 2005, 39, 1731-1735.

Gimbert, L. J.; Haygarth, P. M.; Beckett, R.; Worsfold, P. J.

The influence of sample preparation on observed particle size distributions for contrasting soil suspensions using flow fieldflow fractionation. Environ. Chem. 2006, 3, 184-191.

Gimbert, L. J.; Hamon, R. E.; Casey, P. S.; Worsfold, P. J. Partitioning and stability of engineered $\mathrm{ZnO}$ nanoparticles in soil suspensions using flow field-flow fractionation. Environ. Chem. 2007, 4, 8-10.

Gimbert, L. J.; Haygarth, P. M.; Worsfold, P. J. Application of flow field-flow fractionation and laser sizing to characterize soil colloids in drained and undrained lysimeters. J. Environ. Qual. 2008, 37, 1656-1660.

Gogos, A.; Kaegi, R.; Zenobi, R.; Bucheli, T. D. Capabilities of asymmetric flow field-flow fractionation coupled to multi-angle light scattering to detect carbon nanotubes in soot and soil. Environ. Sci.: Nano. 2014, 1, 584-594.

Gomez-Gonzalez, M. A.; Bolea, E.; O’Day, P. A.; Garcia-Guinea, J.; Garrido, F.; Laborda, F. Combining single-particle inductively coupled plasma mass spectrometry and X-ray absorption spectroscopy to evaluate the release of colloidal arsenic from environmental samples. Anal. Bioanal. Chem. 2016, 408, 5125-5135.

Guzel, N.; Ibrikci, H. Distribution and fractionation of soil phosphorus in particle-size separates in soils of Western Turkey. Commun. Soil Sci. Plant Anal. 1994, 25, 2945-2958.

Han, Q.; Zender, C. Desert dust aerosol age characterized by massage tracking of tracers. J. Geophys. Res. 2010, 115, D22201.

Hassellov, M.; Lyven, B.; Haraldsson, C.; Sirinawin, W. Determination of continuous size and trace element distribution of colloidal material in natural water by on-line coupling of flow field-flow fractionation with ICPMS. Anal. Chem. 1999, 71, 3497-3502.

Hata, M.; Zhang, T.; Bao, L.; Otani, Y.; Bai, Y.; Furuuchi, M. Characteristics of the nanoparticles in a road tunnel. Aerosol Air Qual. Res. 2013, 13, 194-200.

Heithmar, E. M.; Pergantis, S. A. Characterizing concentrations and size distributions of metal-containing nanoparticles in waste water. EPA/600/R-10/117, U.S. Environmental Protection Agency, 2010.

Ho, K. F.; Lee, S. C.; Chow, J. C.; Watson, J. G. Characterization of PM10 and PM2.5 source profiles for fugitive dust in Hong Kong. Atmos. Environ. 2003, 37, 1023-1032.

Hofman, J.; Wuyts, K.; Van Wittenberghe, S.; Brackx, M.; Samson, $R$. On the link between biomagnetic monitoring and leafdeposited dust load of urban trees: relationships and spatial variability of different particle size fractions. Environ. Pollut. 2014, 189, 63-72.

Houghton, J. Global warming. Rep. Prog. Phys. 2005, 68, 1343-1403.

Huynh, K. A.; Siska, E.; Heithmar, E.; Tadjiki, S.; Pergantis, S. A. Detection and quantification of silver nanoparticles at environmentally relevant concentrations using asymmetric flow field-flow fractionation online with single particle inductively coupled plasma mass spectrometry. Anal. Chem. 2016, 88, 4909-4916.

Ivleva, N. P.; Huckele, S.; Weinzierl, B.; Niessner, R.; Haisch, C.; Baumann, T. Identification and characterization of individual airborne volcanic ash particles by Raman microspectroscopy. Anal. Bioanal. Chem. 2013, 405, 9071-9084. 
Jancsek-Turóczi, B.; Hoffer, A.; Nyírő-Kósa, I.; Gelencsér, A. Sampling and characterization of resuspended and respirable road dust. J. Aerosol Sci. 2013, 65, 69-76.

Kadar, E.; Cunliffe, M.; Fisher, A.; Stolpe, B.; Lead, J.; Shi, Z. Chemical interaction of atmospheric mineral dust-derived nanoparticles with natural seawater - EPS and sunlightmediated changes. Sci. Total n. 2014a, 468-469, 265-271.

Kadar, E.; Fisher, A.; Stolpe, B.; Calabrese, S.; Lead, J.; ValsamiJones, E.; Shi, Z. Colloidal stability of nanoparticles derived from simulated cloud-processed mineral dusts. Sci. Total Environ. 2014b, 466-467, 864-870.

Karube, J.; Nakaishi, K.; Sugimoto, H.; Fujihira, M. Size and shape of allophane particles in dispersed aqueous systems. Clays Clay Miner. 1996, 44, 485-491.

Katasonova, O. N.; Fedotov, P. S.; Karandashev, V. K.; Spivakov, B.Ya. Application of rotating coiled columns to the fractionation of soil particles and to the sequential extraction of heavy-metal species from silty, dusty, and sandy fractions. J. Anal. Chem. 2005, 60, 684-690.

Kim, J.; Park, K. Atmospheric aging of Asian dust particles during long range transport. Aerosol Sci. Technol. 2012, 46, 913-924.

Klitzke, S.; Lang, F.; Kaupenjohann, M. Increasing pH releases colloidal lead in a highly contaminated forest soil. Eur. J. Soil Sci. 2008, 59, 265-273.

Koopmans, G. F.; Hiemstra, T.; Regelink, I. C.; Molleman, B.; Comans, R. N. Asymmetric flow field-flow fractionation of manufactured silver nanoparticles spiked into soil solution. J. Chromatogr. A. 2015, 1392, 100-109.

Laborda, F.; Bolea, E.; Jime'nez-Lamana, J. Single particle inductively coupled plasma mass spectrometry: powerful tool for nanoanalysis. Anal. Chem. 2014, 86, 2270-2278.

Lægdsmand, M.; Villholth, K. G.; Ullum, M.; Jensen, K. H. Processes of colloid mobilization and transport in macroporous soil monoliths. Geoderma. 1999, 93, 33-59.

Laidlaw, I.; Steinmetz, M. Introduction to differential sedimentation. In Analytical Ultracentrifugation: Techniques and Methods. Scott, D. L.; Harding, S. E.; Rowe, A. J., Eds. Royal Society of Chemistry: Cambridge, 2005; pp 270-290.

Lee, S.; Bi, X.; Reed, R. B.; Ranville, J. F.; Herckes, P.; Westerhoff, P. Nanoparticle size detection limits by single particle ICP-MS for 40 elements. Environ. Sci. Technol. 2014a, 48, 10291-10300.

Lee, S. H.; Salunke, B. K.; Kim, B. S. Sucrose density gradient centrifugation separation of gold and silver nanoparticles synthesized using Magnolia kobus plant leaf extracts. Biotechnol. Bioprocess Eng. 2014b, 19, 169-174.

Luo, P.; Morrison, I.; Dudkiewicz, A.; Tiede, K.; Boyes, E.; O'Toole, P.; Park, S.; Boxall, A. B. Visualization and characterization of engineered nanoparticles in complex environmental and food matrices using atmospheric scanning electron microscopy. J. Microsc. 2013, 250, 32-41.

Luo, X.; Yu, S.; Li, X. Distribution, availability, and sources of trace metals in different particle size fractions of urban soils in Hong Kong: implications for assessing the risk to human health. Environ. Pollut. 2011, 159, 1317-1326.

Lyven, B.; Hasselov, M.; Turner, D. R.; Haraldsson, C.; Anderson, K. Competition between iron- and carbon-based colloidal carriers for trace metals in a freshwater assessed using flow field-flow fractionation coupled to ICPMS. Geochim. Cosmochim. Acta. 2003, 67, 3791-3802.
Madrid, F.; Biasioli, M.; Ajmone-Marsan, F. Availability and bioaccessibility of metals in fine particles of some urban soils. Arch. Environ. Contam. Toxicol. 2008, 55, 21-32.

Murphy, D. M.; Garbarino, J. R.; Taylor, H. W.; Hart, B. T.; Beckett, R. Determination of size and element composition distributions of complex colloids by sedimentation field-flow fractionationinductively coupled plasma mass spectrometry. J. Chromatogr. 1993, 642, 459-467.

Navratilova, J.; Praetorius, A.; Gondikas, A.; Fabienke, W.; v.d. Kammer F.; Hofmann, T. Detection of engineered copper nanoparticles in soil using single particle ICP-MS. Int. J. Environ. Res. Public Health. 2015, 12, 15756-15768.

Nishimura, S.; Noguchi, T.; Shindo, H. Distribution of charred plant fragments in particle size fractions of Japanese volcanic ash soils. Soil Sci. Plant Nutr. 2008, 54, 490-494.

Nomizu, T.; Kaneco, S.; Tanaka, T.; Yamamoto, T.; Kawaguchi H. Determination of femto-gram amounts of zinc and lead in Individual airborne particles by inductively coupled plasma mass spectrometry with direct air-sample introduction. Anal. Sci. 1993, 9, 843-846.

Novoszad, M.; Gerzabek, M.; Lischka, H.; Haberhauer, G.; Jakusch, $M$. Sorption of naphthalene derivatives on to soils from a long-term field experiment: a particle size fractionation and extraction study. Eur. J. Soil Sci. 2007, 58, 26-33.

Olesik, J. W.; Gray, P. J. Considerations for measurement of individual nanoparticles or microparticles by ICP-MS: determination of the number of particles and the analyte mass in each particle. J. Anal. At. Spectrom. 2012, 27, 1143-1155.

Ooki, A.; Nishioka, J.; Ono, T.; Noriki, S. Size dependence of iron solubility of Asian mineral dust particles. J. Geophys. Res. 2009, 114, D03202.

Pace, H. E.; Rogers, N. J.; Jarolimek, C.; Coleman, V.A; Higgins, C. P.; Ranville, J. F. Determining transport efficiency for the purpose of counting and sizing nanoparticles via single particle inductively coupled plasma mass spectrometry. Anal. Chem. 2011, 83, 9361-9369.

Ranville, J. F.; Chittleborough, D. J.; Shanks, F.; Morrison, R. J. S.; Harris, T.; Doss, F.; Beckett, R. Development of sedimentation field-flow fractionation-inductively coupled plasma massspectroscopy for the characterization of environmental colloids. Anal. Chim. Acta. 1999, 381, 315-329.

Regelink, I. C.; Koopmans, G. F.; van der Salm, C.; Weng, L.; van Riemsdijk, W. H. Characterization of colloidal phosphorus species in drainage waters from a clay soil using asymmetric flow field-flow fractionation. J. Environ. Qual. 2013a, 42, 464-473.

Regelink, I. C.; Weng, L. P.; Koopmans, G. F.; van Riemsdijk, W. H. Asymmetric flow field-flow fractionation as a new approach to analyse iron-(hydr)oxide nanoparticles in soil extracts. Geoderma. 2013b, 202-203, 134-141.

Regelink, I. C.; Voegelin, A.; Weng, L.; Koopmans, G. F.; Comans, R. N. J. Characterization of colloidal Fe from soils using field-flow fractionation and Fe K-Edge X-ray absorption spectroscopy. Environ. Sci. Technol. 2014, 48, 4307-4316.

Reid, E. A.; Reid, J. S.; Meier, M. M.; Dunlap, M. R.; Cliff, S. S.; Broumas, A.; Perry, K.; Maring, H. Characterization of African dust transported to Puerto Rico by individual particle and size segregated bulk analysis. J. Geophys. Res. 2003, 108, PRD71-PRD7-22. 
Sangsawong, S.; Waiyawat, W.; Shiowatana, J.; Siripinyanond, A. Field-flow fractionation: an efficient approach for matrix removal of soil extract for inductively coupled plasma optical emission spectrometry. Spectrochim. Acta, Part B. 2011, 66, 476-482.

Santoro, A.; Terzano, R.; Medici, L.; Beciani, M.; Pagnoni, A.; Blo, G. Colloidal mercury $(\mathrm{Hg})$ distribution in soil samples by sedimentation field-flow fractionation coupled to mercury cold vapour generation atomic absorption spectroscopy. J. Environ. Monit. 2012, 14, 138-145.

Schimpf, M.; Caldwell, K. D.; Giddings, J. C. Field-flow fractionation handbook; Wiley: New York, 2000.

Schmidt, M.; Rumpel, C.; Kögel-Knabner, I. Particle size fractionation of soil containing coal and combusted particles. Eur. J. Soil Sci. 1999, 50, 515-522.

Shi, Z.; Krom, M. D.; Bonneville, S.; Baker, A. R.; Jickells, T. D.; Benning, L. G. Formation of iron nanoparticles and increase in iron reactivity in mineral dust during simulated cloud processing. Environ. Sci. Technol. 2009, 43, 6592-6596.

Steinigeweg, D.; Schutz, M.; Salehi, M.; Schlucker, S. Fast and costeffective purification of gold nanoparticles in the 20-250 nm size range by continuous density gradient centrifugation. Small. 2011, 7, 2443-2448.

Stemmer, M.; Gerzabek, M.; Kandeler, E. Organic matter and enzyme activity in particle-size fractions of soils obtained after low-energy sonication. Soil Biol. Biochem. 1998, 30, 9-17.

Tang, Z., Wu, L.; Luo, Y.; Christie, P. Size fractionation and characterization of nanocolloidal particles in soils. Environ. Geochem. Health. 2009, 31, 1-10.

Taylor, H. E.; Garbarino, J. R.; Murphy, D. M.; Beckett, R. Inductively coupled-plasma-mass spectrometry as an element-specific detector for field-flow fractionation particle separation. Anal. Chem. 1992, 64, 2036-2041.

Tepe, N.; Bau, M. Importance of nanoparticles and colloids from volcanic ash for riverine transport of trace elements to the ocean: evidence from glacial-fed rivers after the 2010 eruption of Eyjafjallajökull Volcano, Iceland. Sci. Total Environ. 2014, 488-489, 243-251.

Tolocka, M. P., Lake, D. A.; Johnston, M. V.; Wexler, A. S. Number concentrations of fine and ultrafine particles containing metals. Atmos. Environ. 2004, 38, 3263-3273.

Traversi, D.; Alessandria, L.; Schilirò, T.; Gilli, G. Size-fractionated PM10 monitoring in relation to the contribution of endotoxins in different polluted areas. Atmos. Environ. 2011, 45, 35153521.

Tsao, T.; Chen, Yu.; Sheu, H.; Tzou, Yu.; Chou, Yu.; Wang, M. Separation and identification of soil nanoparticles by conventional and synchrotron X-ray diffraction. Appl. Clay Sci. 2013, 85, 1-7.

Tuoriniemi, J.; Gustafsson, S.; Olsson, E.; Hassellov, M. In situ characterisation of physicochemical state and concentration of nanoparticles in soil ecotoxicity studies using environmental scanning electron microscopy. Environ. Chem. 2014, 11, 367-376.
Turner, B. L.; Kay M. A.; Westermann, D. T. Colloidal phosphorus in surface runoff and water extracts from semiarid soils of the western United States. J. Environ. Qual. 2004, 33, 1464-1472.

v.d. Kammer, F.; Forstner, U. Natural colloid characterization using flow field-flow fractionation followed by multi-detected analysis. Water Sci. Technol. 1998, 37, 173-180.

Worrall, F.; Parker, A.; Rae, J. E.; Johnson, A. C. A study of suspended and colloidal matter in the leachate from lysimeters and its role in pesticide transport. J. Environ. Qual. 1999, 28, 595-604.

Yang, Y.; Long, C.-L.; Li, H.-P.; Wang, Q.; Yang, Z.-G. Analysis of silver and gold nanoparticles in environmental water using single particle-inductively coupled plasma-mass spectrometry. Sci. Total. Environ. 2016, 563, 996-1007.

Yu, K.-M.; Wu, Y.-L.; Fang, K.; Lin, M. Particle size distribution of polychlorinated dibenzo-p-dioxins and dibenzofurans in the ambient air of an electric-arc furnace-dust treatment plant. Environ. Eng. Sci. 2009, 26, 1713-1723.

Zhang, H.; Luo, Y.; Makino, T.; Wu, L.; Nanzyo, M. The heavy metal partition in size-fractions of the fine particles in agricultural soils contaminated by waste water and smelter dust. J. Hazard. Mater. 2013, 248-249, 303-312.

Zhao, P.; Feng, Y.; Zhu, T.; Wu, J. Characterizations of resuspended dust in six cities of North China. Atmos. Environ. 2006, 40, 5807-5814.

Zirkler, D.; Lang, F.; Kaupenjohann, M. "Lost in filtration” - The separation of soil colloids from larger particles. Colloids Surf., A. 2012, 399, 35-40.

\section{Bionotes}

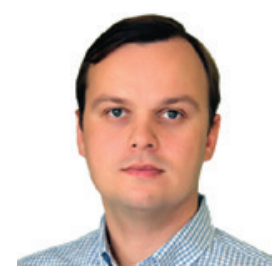

\author{
Mikhail S. Ermolin \\ Vernadsky Institute of Geochemistry and \\ Analytical Chemistry, Russian Academy of \\ Sciences, 19 Kosygin Street, Moscow 119991, \\ Russian Federation; and National University \\ of Science and Technology "MISiS", \\ 4 Leninsky Prospect, Moscow 119049, \\ Russian Federation, \\ mihail.ermolin@gmail.com \\ http://orcid.org/0000-0002-0023-4507
}

Mikhail S. Ermolin graduated from the Department of Nanomaterials and Nanotechnology of Mendeleev University of Chemical Technology of Russia, obtained PhD degree in Chemistry from Vernadsky Institute of Geochemistry and Analytical Chemistry (Moscow, Russia) where he is working now as Research Scientist. $\mathrm{He}$ is also working in the Laboratory of Separation and Pre-Concentration in the Chemical Diagnostics of Functional Materials and Environmental Objects at the National University of Science and Technology “MISiS” (Moscow, Russia) as Senior Research Scientist. His research interests include fractionation and characterization of nano- and microparticles of dust, volcanic ash, and soil. 


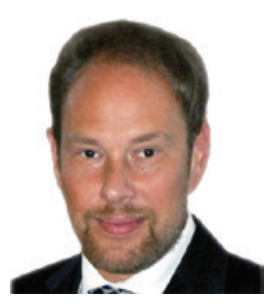

Petr S. Fedotov

Vernadsky Institute of Geochemistry and Analytical Chemistry, Russian Academy of Sciences, 19 Kosygin Street, Moscow 119991, Russian Federation; National University of Science and Technology “MISiS”, 4 Leninsky Prospect, Moscow 119049, Russian Federation

Petr S. Fedotov graduated from the Chemical Faculty of Lomonosov Moscow State University, obtained PhD degree in Chemistry from Vernadsky Institute of Geochemistry and Analytical Chemistry where he is working now as a Leading Research Scientist. He is also Head of the laboratory of separation and preconcentration in the chemical diagnostics of functional materials and environmental objects at the National University of Science and Technology “MISiS". Petr S. Fedotov is President of Chemistry and the Environment Division of International Union of Pure and Applied Chemistry (IUPAC). He is a recognized specialist in dynamic methods of fractionation of metals and metalloids in anthropogenic and environmental solids as well as an expert in methods of separation of nano- and microparticles in liquid media. 